\title{
Managing Forests for Carbon and Timber: A Markov Decision Model of Uneven-Aged Forest Management with Risk
}

\begin{abstract}
:
This paper calculates steady state management decisions that, if followed indefinitely, provide an adaptive strategy that maximizes the value from timber and carbon sequestration when risk is present. By including carbon offsets directly in the objective function of a Markov decision process (MDP) model, we find long-term trade-offs exist between economic and ecological outcomes. An economic supply schedule is provided, which shows an exponential increase in the cost of sequestration. Moderate carbon prices effectively sequester additional $\mathrm{CO}_{2}$ from the atmosphere while having a positive impact on ecological indicators such as size and species diversity. In contrast, high carbon prices promote more of a monoculture in order to maximize expected forest value in the long run from carbon sequestration. This study finds evidence that the optimal adaptive decisions are sensitive to the magnitude of carbon prices, and consequently, so too are ecological outcomes. While some governments acknowledge the influence carbon markets have on the ecological integrity of the forest, fluctuations in carbon prices within a cap-and-trade market likely influence the optimal decision making of the forest manager, and thus, the ecological landscape of the forest itself.
\end{abstract}

Keywords: Markov decision process; Carbon offsets; Management; Diversity; Risk 


\section{INTRODUCTION}

Societal interest in climate change mitigation has opened the door for forest management to play an integral role in reducing atmospheric $\mathrm{CO}_{2}$. Terrestrial ecosystems represent two-fifths of the total exchange of $\mathrm{CO}_{2}$ between earth and the atmosphere, with forests accounting for $80 \%$ (FAO 2014). Clearly, forests are critical in determining the concentration of $\mathrm{CO}_{2}$ in the atmosphere, with human activities related to forest management affecting the globe's $\mathrm{CO}_{2}$ balance. With this in mind, forests can be managed to produce carbon offsets to nullify or offset the impact of a carbon emitting activity (see van Kooten \& Johnston, 2016), facilitated through programs such as the Clean Development Mechanism (CDM) that were introduced to help member nations meet their self-imposed Kyoto targets (see Armano \& Sedjo, 2003).

Forest management can also significantly affect the ecological landscape. A common approach in forestry is to employ even-aged management that promotes clear-cut harvesting of stands of similar age, size and species. While this method is economically favorable in many cases, it is often criticized for failing to preserve the ecological integrity of the forest (Esseen et al., 1997; Kuuluvainen, 2002; Doyon et al., 2005; Xabadia \& Goetz, 2010). Consequently, there is increasing interest in managing the forest for both timber and carbon production, while at the same time, maintaining a more diverse stand structure. Uneven-aged forest management can be used to achieve the best outcome given these competing goals. Such methods include thinning, or only harvesting certain species in certain diameter classes, promoting the ecological integrity of the forest (Kuuluvainen et al., 2012). While more knowledge is required for this management strategy, it can achieve the joint goals of managing forests for profit as well as ecological diversity. Governments appear willing to acknowledge the ecological shortcomings of clearcutting by mandating uneven-aged forest management in carbon offset production, as is the case for the California cap-and-trade scheme (ARB, 2015).

Still, relatively little is known of the long term economic and ecological outcomes of uneven-aged forest management when carbon has value, particularly when accounting for risk in forest growth and market conditions. Early studies extended traditional Faustmann models, which examine optimal replant intervals, to include annual ecosystem benefits (Hartman, 1976) and later to include carbon sequestration (van Kooten et al., 1995). These models assume evenaged forest management, and examine the trade-off between harvesting for profit and ecosystem services (Gutrich \& Howarth, 2007). Van Kooten et al (1995) established that placing value on forest carbon offsets leads to longer rotations and increased carbon sequestration. However, uncertainties involving the effect of disturbance on the production of such offsets still exist, and this can significantly affect forest planning and ultimately the long-term ecological qualities of the forest (Kurz et al., 2008; Lindroth et al., 2009).

The literature concerning the role of risk in forest management is well established (see. e.g. Kant and Alavalapati, 2014, pp. 307-369). Studies that have extended Faustmann models examine the impact of uncertainty on forest management, including risk related to forest growth, as well as uncertainty in timber and carbon markets, and the impact of risk aversion (see Alvarez 
\& Koskela, 2004; Ruszczynski, 2009). Hu (2014) outlines several studies that examine the effect of catastrophic events on optimal forest rotations, but few applications have considered risk and uncertainty in forest carbon offset production. Hu (2014) examines the impact of including carbon offsets on optimal rotation under catastrophic risk in a Faustmann, even-aged framework. Chladni (2006) develops a real options model that includes stochastic wood and carbon prices that follow a mean reverting process. Like the previous studies, their analysis focuses on whether stochastic prices will affect the optimal rotation model, assuming even-aged forest management. They find that the optimal even-aged rotation age varies with the way the stochastic price processes are defined.

As mentioned above, since historical management practices such as clear cutting can have adverse effects on ecosystem services, there is increasing interest in uneven-aged forest management as an alternative to clear cutting methods. Several recent studies have developed non-linear matrix growth models that predict stand growth for different species and size classes of trees (Ralston et al., 2002; Liang et al., 2005), as well as accounting for uncertainly related to weather and pests (Liang et al., 2006). Such growth models have formed the basis of Markov decision process (MDP) models used to find the optimal harvest decisions that maximize the forest value in an environment with multi-dimensional risk (Zhou and Buongiorno, 2011).

While uneven-aged models have been used to account for uncertainty in stand growth, timber prices and interest rates (Zhou et al., 2008; Zhou and Buongiorno, 2011), they have been relatively absent in the literature concerning the ecological effects of placing value on carbon in an uncertain environment. Two studies should be noted. The first is Buongiorno et al. (2012) who place value on carbon in an uneven-aged framework, highlighting the impact on stand structure including the diversity of tree size and species, as well as carbon stocks. This study does not consider uncertainty associated with disturbance and does not provide optimal decisions in a stand-state formulation. The other study is Buongiorno and Zhou (2015) who investigate uneven-aged management with uncertainty associated with disturbance, highlighting economic and ecological trade-offs associated with optimal decision making under risk. Yet, the authors do not include carbon prices directly in the objective function, which prevents conclusions to be drawn on the effects of carbon offset markets on the ecological quality of the forest when faced with risk.

With this in mind, we extend these methods to investigate the impact of uneven-aged forest management when carbon has value on the long term economic and ecological outcomes of the forest. Washington and Oregon state provide a nice case study as they contain a significant proportion of US timberland, and consist of highly productive softwood species, such as Douglas fir (Pseudotsuga menziesii) and Western hemlock (Tsuga heterophylla). Forests in the Pacific North West (PNW) also provide substantial environmental benefits, including wildlife habitat, ecosystem diversity, recreational use and carbon sequestration. This study builds on the current literature by expanding a forest management model of the PNW region (Zou \& Buongiorno, 2008), taking into account stochastic disturbances to stand growth based on past behavior of ecological and climatic shocks. It is the first known study that examines the trade-off between 
carbon sequestration (using carbon prices) and timber in an MDP model, by explicitly including the value of carbon storage in the objective. We can therefore examine how incorporating the ecosystem benefits of the forest will impact optimal silviculture strategies. There are several ways to increase carbon storage due to forests, such as increasing productivity of existing forest lands, planting trees in urban areas, and increasing the use of durable wood products and treatments that can keep carbon stored once the wood is harvested (Birdsey, 1992). However, by examining carbon stored in forests, the focus in this study is on reducing deforestation.

\section{Methods ANd DATA}

The guiding principle of this study is to represent the evolution of the forest ecosystem based upon biophysical variables subject to random disturbance using Markov chains: a random process that describes the frequencies of transition from one state to another on a state space. One can use a Markov decision process (MDP) model to predict the future of the forest state space subject to optimal management strategies and random disturbance. These strategies are a set of rules that describe a decision for each observed state space, and therefore may provide adaptive strategies for achieving different objectives. The novel contribution of this paper is to add carbon prices to the MDP framework, as outline in section 2.3.

\subsection{Growth model structure}

This study builds upon the stochastic growth model and MDP model from Zhou et al. (2008), which is based on previous work developed in Ralston et al. (2003), Liang et al. (2006) and Zhou and Buongiorno (2006). The model predicts stochastic stand growth from 14,794 FIA plots in the the state of Oregon and Washington (Table 1). The stand states of the forested landscape are described by the level of basal area in trees of different sizes and species, with basal area in three tree size classes: small $(10 \mathrm{~cm} \leq \mathrm{dbh}<25 \mathrm{~cm})$, medium $(25 \mathrm{~cm} \leq \mathrm{dbh}<41 \mathrm{~cm})$, and large (dbh $\geq 41$ ); and two species categories (shade tolerant, shade intolerant). Basal area can take on two levels, high or low, indicating above or below average basal area in a given size and species class. The threshold between low and high basal area for shade-tolerant species were 5.85, 5.37, ad $5.39 \mathrm{~m}^{2} \mathrm{ha}^{-1}$ for small, medium and large trees, respectively. The corresponding thresholds for shade-intolerant species were $3.25,2.48$, and $2.84 \mathrm{~m}^{2} \mathrm{ha}{ }^{-1}$. Thus, there are $2^{6}=64$ possible stand states; each stand state is described by a string of six digits. For example, for stand state 001010 , the first three digits show high basal area in large shade tolerant trees, and the last three describe high basal area in medium shade intolerant trees.

\section{< INSERT TABLE 1 ABOUT HERE >}

The probability matrix that describes the frequencies of transition from state $s$ to $s$ ' is described by $\mathbf{T}=\left[p\left(s^{\prime} \mid s\right)\right]$. These transition probabilities are taken from Zhou et al. (2008), who employ the following stochastic simulation model of stand growth: 


$$
\mathbf{y}_{t+1}=\mathbf{G}_{t} \mathbf{y}_{t}+\boldsymbol{r}_{\boldsymbol{t}}+\mathbf{u}_{t}
$$

where $\boldsymbol{y}_{t}=\left[y_{i j t}\right]$ is the number of trees per unit area of each species group $i=1, \ldots, m$ and diameter class $j=1, \ldots, \mathrm{n}$ at time $t$. $\mathbf{G}_{t}$ is a state-dependent matrix that describes the probability that a tree of a given species stays alive and grows into a higher size class from $t$ to $t+1 . \mathbf{r}_{t}$ is a measure of recruitment; the number of trees that enter into the smallest age class from $t$ to $t+1$. Finally, $\mathbf{u}_{t}$ is a vector of random disturbance.

The observed disturbances were calculated as the difference between the number of trees estimated by model (1), and the observed number of trees according to the FIA plots. This difference gave rise to a vector of random shocks $\mathbf{u}_{t}$ due to weather, pest, fire, etc., that have affected forest growth during the observed time period. The transition probabilities between stand states $p\left(s^{\prime} \mid s\right)$ were calculated using model (1), with a random draw from $\mathbf{u}_{t}$ via bootstrap simulation. Due to the short time frame, the transition probabilities predicted in this manner reflect low severity, high frequency disturbances. This process was repeated sufficiently to obtain stable probabilities (Table 2).

\section{$<$ INSERT TABLE 2 ABOUT HERE $>$}

\subsection{Optimizing timber revenue}

The goal of the basic MDP model used in previous studies (Zhou et al., 2008, 2011) is to maximize expected net present value of the forest for timber revenue over an infinite horizon. Formally, the model can be solved using linear programming (Hillier \& Lieberman, 1990, p. 787):

$$
\operatorname{Max} N P V=\sum_{s} \sum_{k} R_{s k} Z_{s k}
$$

subject to:

$$
\begin{aligned}
& \sum_{k} z_{s^{\prime} k}-a \sum_{s} \sum_{k} z_{s k} p\left(s^{\prime} \mid s, k\right)=\pi_{s^{\prime}} s^{\prime}=1, \ldots, 64 \\
& z_{s k} \geq 0 \quad \forall s, k,
\end{aligned}
$$

where $z_{s k}$, are the total discounted time of being in state $s$ and making decision $k$, and $R_{s k}$ is the return of being in state $s$ and making decision $k$. The average delivered price of Douglas Fir \#2 sawlogs was $\$ 131.35 / \mathrm{m}^{3}$ in $2015^{1}$ (Random Lengths, 2016). The production associated with decision $k$ was the difference between volume in the pre- and post- harvest state. The discount factor is $\alpha=1 /(1+r)$ where $r$ is the yearly interest rate, which is assumed to be $5 \%$. $\pi_{s^{\prime}}$ is the

\footnotetext{
${ }^{1}$ A conversion factor of $4.53 \mathrm{~m}^{3} / \mathrm{mbf}$ was assumed (USDA, 2015). $\mathrm{mbf}=$ thousand board foot
} 
probability that the stand-price system is initially in state $s^{\prime}$. Given the optimal solution, the best policy is given by:

$$
\mathbf{D}=\frac{z_{s k}}{\sum_{k} z_{s k}}
$$

where $\mathbf{D}=\left[d_{s k}\right]$ is the probability of making decision $k$ in state $s$. The optimal policy is stationary, depending only on the current state, and deterministic $\left(d_{s k}=0\right.$ or 1$)$ : for each state there is only one best decision, with probability 1 . Consequently, the best policy is independent of the initial system state, $\pi_{j}$.

\subsection{Optimizing timber and carbon revenue}

We expand the previous model to include the value of carbon stored in above ground biomass. The mass of $\mathrm{CO}_{2}$ was calculated assuming $50 \%$ of the tree is carbon (Penman et al., 2003), then converted to $\mathrm{CO}_{2}$ using the ratio 44/12 reflecting the atomic weight of of $\mathrm{C}$ (12), and $\mathrm{O}$ (16). As the stand grows to a new state, more carbon is stored, whereas when the forest is thinned, we lose this carbon storage. As such, $C_{s k}$ is added to the model to capture the carbon stored given initial state $s$ and decision $k . C_{s k}$ is then multiplied by the price of carbon, $P^{C O_{2}}$, to explicitly trade-off timber value and carbon storage value when making decision $k$ (i.e. harvesting) given initial state $s$.

While thinning may increase profit from timber, there will be a trade-off as it results in a loss in terms of carbon storage. The optimal policies given the value of both timber and carbon offsets is then obtained by solving the following linear program:

$$
\operatorname{Max} N P V^{\prime}=\sum_{s} \sum_{k}\left(R_{s k}+P^{C O_{2}} C_{s k}\right) z_{s k},
$$

subject to the same constraints as in (3), with the corresponding best policy obtained with equation (4). The expected $\mathrm{NPV}_{s}$ for a particular initial system state $s$, was found be setting the right hand side of (3) to $\pi_{s}=1$ for $s^{\prime}=\mathrm{s}$, and $\pi_{s}=0$ for $s^{\prime} \neq \mathrm{s}$.

\subsection{Effects of policy}

The optimal decision D consists of moving from one state to another, or do nothing. A decision to harvest produces less basal area, less carbon sequestered in the stand, and a different composition of tree species and size. It also generates cash flows associated with the production of timber.

While the best decision (D) is stationary and independent of the initial system state, it will inevitably alter the ecological landscape of the forest. Based on decision D and the frequencies of transition from state $s$ to $s^{\prime}$, denoted by $\mathbf{T}=\left[p\left(s^{\prime} \mid s\right)\right]$, one can determine how management will impact expected long run forest characteristics (Buongiorno \& Zhou, 2015). The steady-state probabilities of no management $\mathbf{P}$ are obtained by solving: 


$$
\mathbf{P}=\mathbf{P} \times \mathbf{T},
$$

where $\mathbf{P}=\left[p_{s}\right]$, which is the probability of being in stand state $s(s=1, \ldots, 64)$ in the long run if no management occurs. Changing $\mathbf{T}$ to reflect different levels of natural disturbance led to different levels of long run stand state probabilities.

Alternatively, let $\mathbf{P}^{*}=\left[p_{s}^{*}\right]$ represent the long run probability of stand state $s$ if we follow decision matrix $\mathbf{D}$, given the original stand state transition matrix $\mathbf{T}$ :

$$
\mathbf{P}^{*}=\mathbf{P}^{*} \times \mathbf{D} \times \mathbf{T} .
$$

The steady state probabilities calculated in this way can then be used to calculate the long run economic and ecological implications of different management strategies, which will vary depending on exogenous inputs including the value of timber and carbon offsets.

One measure of the ecological integrity of the landscape includes forest diversity, which has been applied to similar models of uneven-aged management (Zhou et al., 2008; Buongiorno $\&$ Zhou, 2015). Here, we employ Shannon's index (Shannon, 1948) to measure the diversity of species:

$$
H_{t}^{s}=-\sum_{i=1}^{m} \frac{B_{i t}}{B_{t}} \ln \frac{B_{i t}}{B_{t}},
$$

and tree size diversity:

$$
H_{t}^{d}=-\sum_{j=1}^{n} \frac{B_{j t}}{B_{t}} \ln \frac{B_{j t}}{B_{t}},
$$

where $B_{t}$ is the total basal area per hectare in time $t ; B_{i t}$ is the basal area of species $i$ at time $t$, and $B_{j t}$ is the basal area of size $j$ at time $t$. Species and size diversity are greatest when they are equal, positive measures of basal area in all species and size classes.

The interval between harvests in steady-state may also be calculated. Buongiorno and Zhou (2015) show that if we let $h_{s}^{k}=1$ denote a decision $k$ that called for a harvest in stand state $s$, then the annual probability of a harvest is:

$$
\pi_{h}=\sum_{s} p_{s}^{*} h_{s}^{k},
$$

and the expected cutting cycle is the inverse of the annual probability to harvest:

$$
\mathrm{C}=1 / \pi_{h} .
$$




\section{RESULTS}

\subsection{Best decisions with carbon offsets}

The decisions that maximized net present value associated with timber and carbon offset revenue are summarized in Table 3. The values presented in the table represent the state that the forest stand will move to if best (NPV maximizing) practices are followed, given initial conditions. Each state has a best decision that depends on growth and disturbance, which is stationary over time. With no value for carbon offsets, the majority of optimal decisions are to harvest the land into a state with low basal area in all size and species classes. The incentive in this framework is to harvest for timber value, rather than allowing the forest to grow to a new state. Not surprisingly, positive carbon prices appear to create an incentive to leave more basal area standing in the forest, leading to increased carbon sequestration. For example, with a zero carbon price, it was only optimal to stay in the original state (and not harvest) four times out of 64 initial states. This increased to 12 times for a carbon price of $\$ 15 \mathrm{tCO}_{2}{ }^{-1}$, and 17 times for a price of $\$ 30$ $\mathrm{tCO}_{2}^{-1}$.

In contrast with traditional Faustman rotation age models with carbon (e.g. van Kooten et al., 1995), optimal management strategies are state dependent and not robust across different carbon prices. For example, consider stand state \#17 which has high basal area in large shadeintolerant trees, as well as in small and medium shade-tolerant trees. The optimal decision with a zero carbon price is to harvest the land into a state with low basal area in all size and species classes. Meanwhile, a carbon price of $\$ 15 \mathrm{tCO}_{2}^{-1}$ leads to a reduction in basal area in medium shade-tolerant trees, while a price of $\$ 30 \mathrm{tCO}_{2}^{-1}$ leads to reduction in basal area of the large shade-intolerant trees. Overall, it is no longer optimal to harvest all trees once carbon prices are introduced, but the specific decision may change with carbon prices. Landowners must manage their lands considering the trade-offs between timber and carbon revenue, with the likely evolution of forest growth in mind. Consequently, we capture more details about optimal decision practices that are state dependent when uneven-aged silviculture practices are employed.

\section{$<$ INSERT TABLE 3 ABOUT HERE >}

\subsection{Forest value with carbon offsets}

The value of the forest $\left(10^{3} \$ \mathrm{ha}^{-1}\right)$ derived from equation (5) for all initial stand states is presented in Table 4. With a zero carbon price, only timber has value and the highest forest value is found in stand state \# 64 which has high basal area in all species and size classes. In this environment, the lowest forest value is found in state \# 1, which has low basal area in all size and species classes. Generally, stands with more basal area have higher forest vale. This is intuitive, since the forest manager can harvest more from stands with high total basal area, leading to higher 
revenue. In contrast, when faced with a carbon price of $\$ 30 \mathrm{tCO}_{2}^{-1}$, the initial stand states with the highest expected forest value are states \#33 and \#48. Here, the forest manager makes optimal decisions based upon trading off timber revenue from harvesting, and carbon revenue from not harvesting, with the likely evolution of forest growth in mind. This results in stands with the highest forest value that have a combination of trees with high basal area in some size and species classes, but also with potential for growth to sequester carbon.

\section{< INSERT TABLE 4 ABOUT HERE >}

For all initial states, the value of the forest increases as the price of carbon increases. When considering positive carbon prices, the forest manager can either choose the initial decision and earn the same revenue as if prices were zero, or they can make a different choice if considering the value of carbon increases revenue. The increase in forest value associated with rising carbon prices is proportionally larger in stands with low basal area. Here, the forest manager becomes increasingly concerned with capturing carbon rents and therefore puts less emphasis on current stand volume and more on future growth potential. Inevitably, future growth is influenced by the probability of disturbance.

The results show that contrary to traditional Faustmann models, optimal decision making under risk is state dependent and varies across carbon prices. A main driver of this finding is that the evolution of forest growth inevitably depends on random disturbance. While carbon offsets create additional value to the forest, this value may be larger in stands with high growth potential and low susceptibility to disturbance. That is, adaptive decision making must be employed in order to maximize timber and carbon value when risk is present. Also, while optimal decisions according to Table 3 may move to stand state with higher or lower immediate basal area, the long run amount of carbon stored within the forest always increased with carbon prices.

According to Figure 1, the proportion of forest value associated with carbon offsets increases logarithmically as prime timber producing lands require large incentives to be managed for carbon. A majority of forest value associated with carbon offsets is achieved when the price of carbon reaches approximately $\$ 21.50 \mathrm{tCO}_{2}^{-1}$, given the initial distribution of stand states.

\section{< INSERT FIGURE 1 ABOUT HERE >}

\subsection{Ecological and other effects}

Table 5 shows the predicted steady-state probabilities of being in a given stand state associated with the optimal decisions outline in Table 3, calculated using equation (9). These values may be interpreted as the proportion of the entire forest that would be in such a stand state, if the optimal decisions were followed indefinitely over a long period of time. If carbon has no value, $63.5 \%$ of the forest would eventually be in state \#1 with low basal area in all size and species classes as the lands are managed for timber at a $5 \%$ discount rate. Alternatively, a carbon price of $\$ 15 \mathrm{tCO}_{2}^{-1}$ 
leads to $43.4 \%$ of the forest ending up in state $\# 1$, and $24.9 \%$ if the price of carbon were $\$ 30$ $\mathrm{tCO}_{2}^{-1}$.

\section{< INSERT TABLE 5 ABOUT HERE >}

The standing volume that is expected in the long run is much lower with a zero carbon price than when carbon has value. This value is calculated by taking the steady-state probabilities from (9), and multiplying by the respective expected standing volume from Table 1 . With a zero carbon price, it is expected that $240.5 \mathrm{~m} \mathrm{ha}^{3}$ will remain in the forest in the long run if the forests are managed to maximized net present value. If the value of carbon offsets is $\$ 15 \mathrm{tCO}_{2}^{-1}$, then the expected long run standing volume will rise by $70.3 \mathrm{~m}^{3} \mathrm{ha}^{-1}$. Consistently, an additional 82.3 $\mathrm{m}^{3} \mathrm{ha}^{-1}$ of standing volume would remain under a $\$ 30 \mathrm{tCO}_{2}^{-1}$ carbon offset scheme as compared to the zero carbon scenario.

Equation (9) may also be used to determine the long run additional carbon stored in the forest. Figure 2 shows the amount of $\mathrm{CO}_{2}$ sequestered per ha associated with different carbon offset prices. The cost of carbon sequestration rises exponentially as it is likely that lands with small trees quickly become managed for carbon, while large timber rich lands (which are typically harvested for timber revenue) are converted at higher carbon prices. Carbon stored rises exponentially to approximately $130 \mathrm{tCO}_{2} \mathrm{ha}^{-1}$, associated with a carbon offset price of $\$ 100 \mathrm{tCO}_{2}^{-}$ ${ }^{1}$. Beyond this point, the cost of sequestering an additional unit of carbon rises inexorably as we approach the biophysical limit on carbon stored in this forest. Eventually, a rise in carbon prices would result in an arbitrage opportunity for landowners.

\section{$<$ INSERT FIGURE 2 ABOUT HERE >}

The optimal cutting cycle associated with maximizing net present value is presented in Figure 3 for different carbon prices. Using equations (7), (10), and (11), the optimal average interval between harvests ranged from 5.6 years with a zero carbon price, to 83.2 years for a carbon price of $\$ 150 \mathrm{tCO}_{2}^{-1}$. This differs from Buongiorno et al. (2012) who found a 5-year cutting cycle led to higher net present value as compared to a 20 -year cycle, when minimum bounds are placed on $\mathrm{CO}_{2}$ sequestration within an uneven-aged framework. The current study, in contrast, does not pre-specify harvest intervals, but rather calculates them endogenously in order to maximize net present value as carbon prices are integrated into the objective. Buongiorno and Zhou (2015) allow the cutting cycle to be endogenous, but fail to integrate carbon prices directly into the objective. Nonetheless, they conclude that a cutting cycle of 86-years is optimal for maximizing $\mathrm{CO}_{2}$ sequestration in an uneven-aged framework with risk. While this cutting cycle is consistent with our findings, we are able to show that the cutting cycle increases logarithmically across carbon prices.

\section{< INSERT FIGURE 3 ABOUT HERE >}


Including the value of carbon in the model will have long run impacts on the forest composition, and also many ecological indicators. Several other long run ecological effects of maximizing timber and carbon offset value are presented in Figure 4. First, the amount of annual harvest $\left(\mathrm{m}^{3} \mathrm{ha}^{-1} \mathrm{yr}^{-1}\right)$ falls rapidly with carbon prices up to approximately $\$ 30 \mathrm{tCO}_{2}^{-1}$, after which a more modest negative relationship persists. That is, carbon offsets are initially supplied through a reduction in harvests.

Second, the basal area in large trees first falls with carbon prices, then rises to more than offset this original fall. Perhaps one explanation behind this nonlinear relationship is that at lower prices, there is a real trade-off between managing for timber and carbon. Large trees may be harvested not only to produce timber, but also encourage future growth in order to sequester carbon. At higher prices, the benefit associated with timber production is insufficient to offset the potential benefits associated with carbon offset production, and thus, we observe a greater number of large trees remaining in the forest. This turning point appears to first occur at carbon prices of around $\$ 50 \mathrm{tCO}_{2}^{-1}$, and plateaus around $\$ 100 \mathrm{tCO}_{2}^{-1}$.

Third, species and size diversity using Shannon's index appear to follow a similar trend; when carbon prices are low, we observe increases in diversity, but this is followed by declines in diversity as the price of carbon rises. One factor leading to this relationship includes the trade-off between timber and carbon revenue. For zero carbon prices, the forest is managed purely for timber, promoting the harvest of large trees. For moderate carbon prices, the forest is managed for a medley of timber production and carbon offsets, promoting a more diverse range of species and size classes. Finally, with rising carbon prices, a majority of the forest is managed for carbon sequestration, creating incentives for similar size and species classes with large potential to sequester carbon.

The results in figure 4 are qualitatively similar to those found in Buongiorno et al (2012), which is interesting given that we consider a different model and region. Further, their analysis considers average values over a 5 or 20 year cutting cycle, whereas we capture long run characteristics of the forest. One notable difference is that we capture an initial increase in diversity as prices rise, followed by a reduction in diversity at higher prices. Further, we find that size diversity will fall as carbon prices rise, since there is an incentive in the long run to have more large trees for carbon storage.

\section{< INSERT FIGURE 4 ABOUT HERE >}

\section{Conclusion}

The objective of this study is to investigate the long term economic and ecological outcomes of uneven-aged forest management when carbon has value and the forest is subject to random disturbance. To achieve this objective, this study builds upon an existing stochastic growth model and MDP model to include carbon offsets directly in the objective function. The model calculated steady state decisions that, if followed indefinitely, provide an adaptive strategy that 
maximize the value obtained from producing timber and sequestering carbon. Consequently, the expected long term evolution of the forested landscape is provided, including the likely ecological trade-offs associated with pursuing timber and carbon offset production.

Moderate carbon offset prices are effective at sequestering a significant amount of $\mathrm{CO}_{2}$ in the long run, while promoting many other ecological qualities of the forested landscape including size and species diversity. At such prices, the forest continues to be managed primarily for timber value. For carbon prices above an estimated $\$ 21.50 \mathrm{tCO}_{2}^{-1}$, the forest begins to be managed primarily for carbon sequestration value. While additional $\mathrm{CO}_{2}$ is sequestered, ecological qualities including species and size diversity appear to be compromised, as high carbon offset prices promote more of a monoculture to maximize expected forest value in the long run.

As society acknowledges the ecological shortcomings of clear-cutting, uneven-aged forest management will inevitably become more prevalent. With this in mind, the California Air Resources Board (ARB) adopted regulations in 2011 for a cap-and-trade program whereby large industrial emitters may use forest carbon offsets to comply with emissions regulations. According to the California ARB's protocol on forest carbon offsets, sustainable long-term harvesting practices must be demonstrated including the use of uneven-aged silviculture practices (ARB, 2015). As of 2016, 70\% of compliance credits within California were supplied by U.S. forest projects (ARB, 2016), with a carbon price ranging from $\$ 11.55$ to $\$ 22.50 \mathrm{tCO}_{2}^{-1}$ (ICE, 2016). While California's program emphasizes the importance of promoting sustainable forest management practices, they acknowledge more work is needed to better understand how management changes associated with carbon offsets may affect long-term ecological qualities of the forest.

The results presented in this study conclude that carbon offsets encourage adaptive management decisions within an uneven-aged framework with risk that inevitably will affect the long run ecological landscape of the forest. Furthermore, this study finds evidence that the adaptive strategies themselves are sensitive to the magnitude of carbon prices, and consequently, so too are ecological outcomes. As a result, fluctuations in carbon prices within a cap-and-trade market likely influence the optimal decision making of the forest manager, and thus, the ecological landscape of the forest. While this evidence does not necessarily support a carbon tax over a cap-and-trade system, it does support the need to better understand the impact of price movements within carbon markets. Future work could include stochastic carbon prices into the stochastic MDP framework presented in this study to shed more light on this issue.

Furthermore, the optimal adaptive strategies outlined in this study assume risk neutrality whereby the landowner is only interested in maximizing the expected value associated with timber and carbon sequestration. Future work may wish to include risk aversion, as outlined in Ruszczynski (2009), who proposes a method to integrate risk aversion within a similar MDP framework as the one presented here. 


\section{ACKNOWLEDGEMENTS:}

The preparation of this manuscript was supported in part by USDA McIntire-Stennis fund WIS01899. We are also grateful to Joseph Buongiorno for his collaboration and review comments. Any remaining error is the sole responsibility of the authors. 


\section{REFERENCES}

Alvarez, L.H.R., and E. Koskela. 2004. Does risk aversion accelerate optimal forest rotation under uncertainty. CESIFO Working Paper No. 1285.

Armano, M., and R. Sedjo. 2003. Forest carbon sinks: European Union, Japanese, and Canadian approaches. Resources for the future, October 2003: RFF DP 03-41.

[ARB, 2015] Air Resource Board; California Environmental Protection Agency, 2015. Compliance Offset Protocol U.S. Forest Projects. June 25, 2015.

[ARB, 2016] Air Resource Board; California Environmental Protection Agency, 2016. http://www.arb.ca.gov/cc/capandtrade/offsets/offsets.htm. [accessed June 15, 2016].

Birdsey, R.A. 1992. Carbon and storage and accumulation in United States forest ecosystems. United States Department of Agriculture Forest Service General Technical Report WO59 (1992).

Buongiorno, J., E.A. Halvorsen, O.M. Bollandsas, T. Gobakken, and O. Hofstad. 2012. Optimizing management regimes for carbon storage and other benefits in uneven-aged stands dominated by Norway spruce, with a derivation of the economic supply of carbon storage. Scandinavian Journal of Forest Research, 2012; 27: 460-473.

Buongiorno, J. and M. Zhou. 2015. Adaptive economic and ecological forest management under risk. Forest Ecosystems 2(4).

Chladni, Z. 2006. Determination of optimal rotation period under stochastic wood and carbon prices. Forest Policy and Economics 9: 1031-1045.

Doyon, F., D. Gagnon, and J. Giroux. 2005. Effects of strip and single-tree selection cutting on brids and their habitat in southwestern Quebec northern hardwood forest. Forest Ecology and Management 209(1-2): 101-116.

Esseen P.A., B. Ehnström, L. Ericson, and K. Sjöberg. 1992. Boreal forests. Ecological Bulletins 46:16-47.

[FAO] Food and Agriculture Organization of the United Nations, 2014. Climate Change and Forests. http://www.fao.org/docrep/003/y0900e/y0900e06.htm [accessed May 15, 2015].

Gutrich, J., and R.B. Howarth. 2007. Carbon sequestration and the optimal management of New Hampshire timber stands. Ecological Economics 62: 441-450.

Hartman, R. (1976). The harvesting decision when a standing forest has value. Economic Inquiry 14(1), 52-58.

Hillier, F., and G.J. Lieberman. 1990. Introduction to operations research, $6^{\text {th }}$ ed. McGraw-Hill, New York, NY.

$\mathrm{Hu}, \mathrm{L}$ (2014) Economic analysis of carbon sequestration under catastrophic risk and price uncertainty in Kentucky. Theses and Dissertations--Agricultural Economics. Paper 25. http://uknowledge.uky.edu/agecon_etds/25

[ICE, 2016] Intercontinental Exchange. 2016. California carbon allowance end of day reports. https://www.theice.com/marketdata/reports/142 [accessed June 15, 2016]. 
Kant, S., and J. Alavalapati (Eds). 2014. Handbook of forest resource economics. Routledge.

Kuuluvainen, T. 2002. Natural variability of forests as a reference for restoring and managing biological diversity in boreal Fennoscandia. Silva Fennica 36:97-125.

Kuuluvainen, T., O. Tahvonen, and T. Aakala. 2012. Even-aged and uneven-aged forest management in boreal Fennoscandia: A review. Ambio 41(7): 720-737.

Kurz, W.A., C.C.Dymond, G.Stinson, G.J. Rampley, E.T. Neilson, A.L. Carroll, T. Ebata, and L. Safranyik. 2008. Mountain pine beetle and forest carbon feedback to climate change. Nature 452: 987-990.

Liang, J., J. Buongiorno, and R.A. Monserud. 2005. Growth and yield of all-aged Douglas-fir western hemlock stands: a matrix model with stand diversity effects. Canadian Journal of Forest Research 35: 2368-2381.

Liang, J., J. Buongiorno, and R.A. Monserud. 2006. Bootstrap simulation and response surface optimization of management regimes for Douglas-fir/western hemlock Stands. Forest Science 52.5: 579-594.

Lindroth, A., F. Lagergren, A. Grelle, L. Klemedtsson, O. Langvall, P. Weslien, and J. Tuulik. 2009. Storms can cause Europe-wide reduction in forest carbon sink. Global Change Biology 15: 346-355.

Penman, J., M. Gytarsky, T. Hiraishi, T. Krug, T. Kruger, R. Pipatti, et al. (Eds). 2003). Good practice guidance for land use, land-use change and forestry. Kanagawa: Institute for Global Environmental strategies (IGES) for the IPCC. http://www.ipccnggip.iges.or.jp/public/gpglulucf/gpglulucf.html [ accessed June 15, 2016].

Ralston, R., J. Buongiorno, B. Schulte, and J. Fried. 2003. Non-linear matrix modeling of forest growth with permanent plot data: the case of uneven-aged Douglas-fir stand. International Transactions in Operational Research 10: 461-482.

Random Lengths. 2016. The weekly report on North American forest products markets. April 8, 2016. Vol. 72: 14.

Ruszczynski, A., 2009. Risk-averse dynamics programming for Markov decision processes. Mathematical Programming, Series B 125, 511-526.

[USDA] United Sates Department of Agriculture. 2015. Production, prices, employment and trade in Northwest forest industries, all quarters 2013. X. Zhang. Pacific Northwest Research Station. PNW-RB-266.

van Kooten, G.C., 1995. Effect of carbon taxes and subsidies on optimal forest rotation age and supply of carbon services. American Journal of Agricultural Economics 177(2): 365-374.

van Kooten, G.C. and C.M.T. Johnston. 2016. The economics of forest carbon offsets. Annual Review of Resource Economics. Vol. 8: November 2016.

Xabadia, A., and R.U. Goetz. 2010. The optimal selective logging regime and the Faustmann formula. Journal of Forest Economics 16: 63-82.

Zhou, M. and J. Buongiorno. 2001. Effects of stochastic interest rates in decision making under risk: A Markov decision process model for forest management. Forest Policy and Economics 13: 402-410. 
Zhou, M., J. Buongiorno, and J. Liang. 2008. Economic and ecological effects of diameter caps: a Markov decision model for Douglas-fir/western hemlock forests. Forest Science 54.4: 397-407. 
Table 1: Frequency of FIA plots, expected volume and basal area. Source: Zhou et al. (2008).

\begin{tabular}{|c|c|c|c|c|c|c|c|}
\hline $\begin{array}{l}\text { Stand } \\
\text { state } \\
\# \\
\end{array}$ & $\begin{array}{c}\text { Frequency of } \\
\text { FIA } \\
\text { plots in this } \\
\text { stand state }\end{array}$ & $\begin{array}{c}\text { Expected } \\
\text { total } \\
\text { volume } \\
\left(\mathrm{m}^{3} \mathrm{ha}^{-1}\right) \\
\end{array}$ & $\begin{array}{c}\text { Expected } \\
\text { total basal } \\
\text { area } \\
\left(\mathrm{m}^{2} \mathrm{ha}^{-1}\right)\end{array}$ & $\begin{array}{c}\text { Stand } \\
\text { state } \\
\#\end{array}$ & $\begin{array}{c}\text { Frequency of } \\
\text { FIA } \\
\text { plots in this } \\
\text { stand state }\end{array}$ & $\begin{array}{c}\text { Expected } \\
\text { total } \\
\text { volume } \\
\left(\mathrm{m}^{3} \mathrm{ha}^{-1}\right) \\
\end{array}$ & $\begin{array}{c}\text { Expected } \\
\text { total basal } \\
\text { area } \\
\left(\mathrm{m}^{2} \mathrm{ha}^{-1}\right)\end{array}$ \\
\hline 1 & 0.066 & 234.2 & 18.2 & 33 & 0.032 & 475.1 & 63.1 \\
\hline 2 & 0.015 & 353.8 & 32.3 & 34 & 0.001 & 399.5 & 53.5 \\
\hline 3 & 0.055 & 248.2 & 21.1 & 35 & 0.005 & 365.9 & 31.1 \\
\hline 4 & 0.004 & 375.3 & 49.3 & 36 & 0.004 & 417.2 & 53.7 \\
\hline 5 & 0.002 & 385.6 & 50.4 & 37 & 0.016 & 259.3 & 26.3 \\
\hline 6 & 0.011 & 351.9 & 28.7 & 38 & 0.001 & 410.7 & 58.7 \\
\hline 7 & 0.011 & 403.3 & 50.1 & 39 & 0.012 & 377.0 & 34.0 \\
\hline 8 & 0.031 & 245.3 & 20.9 & 40 & 0.011 & 428.4 & 56.4 \\
\hline 9 & 0.002 & 396.7 & 54.0 & 41 & 0.002 & 389.3 & 55.6 \\
\hline 10 & 0.025 & 363.1 & 30.3 & 42 & 0.013 & 440.6 & 66.5 \\
\hline 11 & 0.027 & 414.4 & 53.7 & 43 & 0.001 & 407.0 & 54.3 \\
\hline 12 & 0.024 & 426.7 & 63.6 & 44 & 0.011 & 458.3 & 65.3 \\
\hline 13 & 0.003 & 393.0 & 49.8 & 45 & 0.002 & 400.4 & 57.7 \\
\hline 14 & 0.021 & 444.4 & 63.6 & 46 & 0.017 & 451.7 & 67.3 \\
\hline 15 & 0.004 & 386.4 & 52.2 & 47 & 0.003 & 418.1 & 54.7 \\
\hline 16 & 0.024 & 437.8 & 5.0 & 48 & 0.028 & 469.5 & 66.8 \\
\hline 17 & 0.005 & 404.2 & 52.3 & 49 & 0.041 & 367.8 & 35.3 \\
\hline 18 & 0.043 & 455.5 & 63.9 & 50 & 0.003 & 419.1 & 57.4 \\
\hline 19 & 0.002 & 405.2 & 50.4 & 51 & 0.013 & 385.5 & 40.7 \\
\hline 20 & 0.007 & 371.5 & 37.9 & 52 & 0.010 & 436.9 & 56.6 \\
\hline 21 & 0.007 & 422.9 & 52.9 & 53 & 0.024 & 378.9 & 38.7 \\
\hline 22 & 0.008 & 365.0 & 35.9 & 54 & 0.004 & 430.3 & 61.9 \\
\hline 23 & 0.002 & 416.3 & 53.8 & 55 & 0.026 & 396.6 & 44.0 \\
\hline 24 & 0.012 & 382.7 & 39.7 & 56 & 0.025 & 448.0 & 58.9 \\
\hline 25 & 0.016 & 434.0 & 53.8 & 57 & 0.022 & 408.9 & 55.1 \\
\hline 26 & 0.013 & 394.9 & 50.9 & 58 & 0.025 & 460.2 & 65.0 \\
\hline 27 & 0.018 & 446.3 & 62.4 & 59 & 0.011 & 426.6 & 56.0 \\
\hline 28 & 0.008 & 412.6 & 51.4 & 60 & 0.015 & 477.9 & 64.3 \\
\hline 29 & 0.018 & 464.0 & 62.0 & 61 & 0.019 & 420.0 & 57.9 \\
\hline 30 & 0.011 & 406.0 & 53.8 & 62 & 0.023 & 471.4 & 66.6 \\
\hline 31 & 0.017 & 457.4 & 64.5 & 63 & 0.022 & 437.7 & 58.5 \\
\hline 32 & 0.016 & 423.8 & 54.8 & 64 & 0.037 & 489.1 & 65.8 \\
\hline
\end{tabular}


Table 2: Transition probabilities between stand states. Source: Zhou et al. (2008).

\begin{tabular}{|c|c|c|}
\hline $\begin{array}{l}\text { Stand state } \\
\text { at } t\end{array}$ & $\begin{array}{l}\text { Stand } \\
\text { Composition }^{\mathrm{a}}\end{array}$ & Stand state at $\mathrm{t}+1$ (transition probability) \\
\hline 1 & 000000 & $1(0.79), 3(0.01), 5(0.06), 17(0.01), 33(0.11)$ \\
\hline 2 & 010000 & $1(0.01), 17(0.81), 19(0.03), 21(0.03), 25(0.04), 49(0.06)$ \\
\hline 3 & 100000 & $1(0.04), 33(0.85), 35(0.01), 37(0.03), 49(0.06)$ \\
\hline 4 & 001000 & $9(0.83), 10(0.04), 11(0.03), 12(0.01), 13(0.03), 25(0.02), 41(0.03)$ \\
\hline 5 & 000001 & $1(0.78), 4(0.03), 6(0.07), 10(0.02), 14(0.01), 18(0.04), 34(0.04)$ \\
\hline 6 & 000010 & $1(0.02), 3(0.80), 5(0.02), 7(0.07), 11(0.01), 19(0.03), 35(0.03)$ \\
\hline 7 & 000011 & $2(0.01), 4(0.88), 8(0.05), 12(0.01), 20(0.02), 36(0.02)$ \\
\hline 8 & 000100 & $1(0.04), 5(0.82), 7(0.07), 21(0.02), 37(0.04)$ \\
\hline 9 & 000101 & $\begin{array}{l}2(0.03), 4(0.01), 6(0.82), 8(0.04), 10(0.01), 14(0.02), 22(0.03) \text {, } \\
34(0.01), 38(0.04)\end{array}$ \\
\hline 10 & 000110 & $3(0.05), 5(0.01), 7(0.84), 8(0.03), 15(0.01), 23(0.03), 39(0.04)$ \\
\hline 11 & 000111 & $4(0.02), 8(0.91), 16(0.01), 24(0.02), 40(0.03)$ \\
\hline 12 & 001001 & $10(0.88), 12(0.02), 14(0.04), 26(0.02), 42(0.03)$ \\
\hline 13 & 001010 & $9(0.04), 11(0.76), 12(0.07), 15(0.02), 27(0.02), 43(0.03)$ \\
\hline 14 & 001011 & $10(0.04), 12(0.84), 16(0.04), 28(0.02), 44(0.04)$ \\
\hline 15 & 001100 & $9(0.02), 13(0.83), 14(0.03), 15(0.04), 29(0.04), 45(0.03)$ \\
\hline 16 & 001101 & $10(0.03), 14(0.88), 16(0.03), 30(0.02), 46(0.04)$ \\
\hline 17 & 001110 & $11(0.02), 13(0.01), 15(0.83), 16(0.08), 31(0.02), 47(0.03)$ \\
\hline 18 & 001111 & $12(0.02), 14(0.02), 16(0.90), 32(0.02), 48(0.04)$ \\
\hline 19 & 010001 & $2(0.04), 18(0.76), 20(0.05), 22(0.04), 26(0.04), 50(0.05)$ \\
\hline 20 & 010010 & $3(0.03), 17(0.03), 19(0.76), 20(0.02), 23(0.04), 27(0.05), 51(0.04)$ \\
\hline 21 & 010011 & $4(0.04), 18(0.02), 20(0.81), 24(0.02), 28(0.03), 52(0.05)$ \\
\hline 22 & 010100 & $5(0.03), 17(0.03), 21(0.77), 23(0.07), 25(0.03), 53(0.05), 55(0.01)$ \\
\hline 23 & 010101 & $6(0.04), 18(0.04), 22(0.77), 24(0.05), 26(0.01), 30(0.04), 54(0.05)$ \\
\hline 24 & 010110 & $7(0.04), 19(0.03), 21(0.01), 23(0.78), 24(0.03), 31(0.05), 55(0.05)$ \\
\hline 25 & 010111 & $8(0.04), 20(0.02), 22(0.02), 24(0.85), 32(0.02), 56(0.04)$ \\
\hline 26 & 011000 & $9(0.02), 25(0.84), 26(0.03), 27(0.02), 29(0.04), 57(0.04)$ \\
\hline 27 & 011001 & $10(0.05), 26(0.84), 28(0.02), 30(0.04), 58(0.04)$ \\
\hline 28 & 011010 & $11(0.02), 25(0.02), 27(0.80), 28(0.06), 31(0.04), 59(0.03)$ \\
\hline 29 & 011011 & $12(0.05), 26(0.04), 28(0.82), 32(0.04), 60(0.03)$ \\
\hline 30 & 011100 & 13(0.03), 25(0.04), 29(0.82), 30(0.03), 31(0.03), 61(0.04) \\
\hline 31 & 011101 & $14(0.06), 26(0.03), 30(0.84), 32(0.03), 62(0.04)$ \\
\hline 32 & 011110 & $15(0.01), 27(0.02), 29(0.01), 31(0.85), 32(0.05), 63(0.04)$ \\
\hline 33 & 011111 & $16(0.05), 28(0.03), 30(0.02), 32(0.85), 64(0.04)$ \\
\hline 34 & 100001 & $\begin{array}{l}2(0.05), 6(0.01), 18(0.01), 34(0.74), 36(0.05), 38(0.06), 42(0.01), \\
50(0.08)\end{array}$ \\
\hline 35 & 100010 & $3(0.02), 19(0.01), 33(0.03), 35(0.75), 36(0.02), 39(0.04), 51(0.10)$ \\
\hline 36 & 100011 & $4(0.05), 34(0.03), 36(0.80), 40(0.05), 44(0.02), 52(0.05)$ \\
\hline
\end{tabular}




\begin{tabular}{|c|c|c|}
\hline 37 & 100100 & $5(0.03), 33(0.03), 37(0.78), 39(0.05), 53(0.08)$ \\
\hline 38 & 100101 & $\begin{array}{l}6(0.07), 8(0.01), 34(0.01), 36(0.01), 38(0.75), 40(0.06), 46(0.03), \\
48(0.01), 54(0.05), 56(0.01)\end{array}$ \\
\hline 39 & 100110 & $7(0.04), 35(0.02), 37(0.01), 39(0.80), 40(0.02), 47(0.01), 55(0.09)$ \\
\hline 40 & 100111 & $8(0.05), 24(0.01), 36(0.02), 38(0.01), 40(0.85), 48(0.01), 56(0.04)$ \\
\hline 41 & 101000 & $9(0.04), 41(0.73), 42(0.07), 43(0.02), 45(0.03), 57(0.08), 59(0.01)$ \\
\hline 42 & 101001 & $10(0.05), 42(0.86), 46(0.05), 58(0.02)$ \\
\hline 43 & 101010 & $\begin{array}{l}\text { 11(0.03), 12(0.01), 41(0.04), 42(0.01), 43(0.73), 44(0.08), 47(0.05), } \\
59(0.02)\end{array}$ \\
\hline 44 & 101011 & $12(0.06), 42(0.04), 44(0.81), 46(0.01), 48(0.04), 60(0.02)$ \\
\hline 45 & 101100 & 13(0.04), 15(0.01), 41(0.04), 45(0.77), 46(0.05), 47(0.03), 61(0.06) \\
\hline 46 & 101101 & $14(0.05), 42(0.03), 46(0.88), 48(0.02), 62(0.02)$ \\
\hline 47 & 101110 & $\begin{array}{l}15(0.02), 16(0.01), 43(0.03), 45(0.01), 47(0.77), 48(0.07), 61(0.01), \\
63(0.05)\end{array}$ \\
\hline 48 & 101111 & $16(0.04), 44(0.02), 46(0.02), 48(0.88), 64(0.02)$ \\
\hline 49 & 110000 & $17(0.03), 33(0.01), 49(0.87), 51(0.02), 53(0.04), 57(0.02)$ \\
\hline 50 & 110001 & $18(0.03), 34(0.01), 50(0.82), 52(0.03), 54(0.05), 58(0.04)$ \\
\hline 51 & 110010 & $19(0.03), 35(0.01), 49(0.04), 51(0.81), 52(0.02), 55(0.04), 59(0.03)$ \\
\hline 52 & 110011 & $20(0.04), 36(0.02), 50(0.02), 52(0.86), 56(0.04), 60(0.02)$ \\
\hline 53 & 110100 & $21(0.02), 37(0.01), 49(0.03), 53(0.84), 55(0.06), 61(0.03)$ \\
\hline 54 & 110101 & $22(0.02), 38(0.01), 50(0.02), 54(0.87), 56(0.03), 62(0.04)$ \\
\hline 55 & 110110 & $23(0.03), 39(0.01), 51(0.02), 53(0.01), 55(0.85), 56(0.03), 63(0.04)$ \\
\hline 56 & 110111 & $24(0.03), 40(0.02), 52(0.02), 54(0.01), 56(0.90), 64(0.02)$ \\
\hline 57 & 111000 & $25(0.03), 41(0.01), 57(0.87), 58(0.03), 59(0.02), 61(0.04)$ \\
\hline 58 & 111001 & $26(0.03), 42(0.02), 58(0.88), 60(0.02), 62(0.04)$ \\
\hline 59 & 111010 & $27(0.03), 57(0.04), 59(0.83), 60(0.04), 63(0.04)$ \\
\hline 60 & 111011 & $26(0.01), 28(0.05), 44(0.02), 58(0.04), 60(0.81), 64(0.06)$ \\
\hline 61 & 111100 & $29(0.03), 57(0.04), 61(0.85), 62(0.02), 63(0.04)$ \\
\hline 62 & 111101 & $30(0.03), 46(0.03), 58(0.04), 62(0.87), 64(0.02)$ \\
\hline 63 & 111110 & $31(0.04), 47(0.01), 59(0.02), 61(0.03), 63(0.85), 64(0.04)$ \\
\hline 64 & 111111 & $32(0.04), 48(0.03), 60(0.02), 62(0.02), 64(0.88)$ \\
\hline
\end{tabular}

${ }^{a}$ The first three digits refer to small, medium, or large trees of the shade-intolerant species; the last three refer to small, medium, or large trees of the shade-tolerant species. $0=$ low basal area; $1=$ high basal area. 
Table 3: Optimal decisions that maximized net present value of each stand state under different carbon prices.

\begin{tabular}{|c|c|c|c|c|c|c|c|}
\hline \multirow{2}{*}{$\begin{array}{l}\text { Stand } \\
\text { State }\end{array}$} & \multicolumn{3}{|c|}{ Carbon Price $\left(\$ / \mathrm{tCO}_{2}\right)$} & \multirow{2}{*}{$\begin{array}{l}\text { Stand } \\
\text { State }\end{array}$} & \multicolumn{3}{|c|}{ Carbon Price $\left(\$ / \mathrm{tCO}_{2}\right)$} \\
\hline & 0 & 15 & 30 & & 0 & 15 & 30 \\
\hline 1 & -- & -- & -- & 33 & 1 & 29 & 28 \\
\hline 2 & 1 & 1 & 1 & 34 & 3 & -- & -- \\
\hline 3 & -- & 1 & -- & 35 & 3 & 3 & 3 \\
\hline 4 & 1 & -- & -- & 36 & -- & 34 & 34 \\
\hline 5 & 1 & 1 & -- & 37 & -- & 1 & -- \\
\hline 6 & 1 & 1 & 1 & 38 & 37 & 34 & 37 \\
\hline 7 & 1 & 1 & 5 & 39 & 37 & 35 & 37 \\
\hline 8 & 1 & 1 & 1 & 40 & 37 & 36 & 38 \\
\hline 9 & 1 & 8 & -- & 41 & 3 & 1 & -- \\
\hline 10 & 1 & -- & -- & 42 & 3 & -- & 34 \\
\hline 11 & 1 & -- & 10 & 43 & 3 & 1 & 3 \\
\hline 12 & 1 & -- & 5 & 44 & 3 & 1 & 3 \\
\hline 13 & 1 & -- & 6 & 45 & 37 & 15 & 37 \\
\hline 14 & 1 & 6 & 7 & 46 & 37 & 38 & 38 \\
\hline 15 & 1 & -- & -- & 47 & 37 & 1 & -- \\
\hline 16 & 1 & 15 & 15 & 48 & 37 & 45 & 40 \\
\hline 17 & 1 & 15 & 10 & 49 & 3 & 3 & 3 \\
\hline 18 & 1 & 11 & 17 & 50 & 3 & 34 & 49 \\
\hline 19 & 1 & -- & -- & 51 & 3 & 35 & 49 \\
\hline 20 & 1 & -- & -- & 52 & 3 & 26 & 36 \\
\hline 21 & 1 & 6 & 20 & 53 & 37 & -- & 37 \\
\hline 22 & 1 & 2 & -- & 54 & 37 & 53 & 53 \\
\hline 23 & 1 & 22 & 9 & 55 & 37 & 53 & 53 \\
\hline 24 & 1 & 20 & 10 & 56 & 37 & 20 & 40 \\
\hline 25 & 1 & 2 & 24 & 57 & 3 & 41 & 3 \\
\hline 26 & 1 & 4 & -- & 58 & 3 & 27 & 42 \\
\hline 27 & 1 & 26 & -- & 59 & 3 & 28 & 43 \\
\hline 28 & 1 & 20 & 20 & 60 & 3 & 28 & 58 \\
\hline 29 & 1 & 20 & 27 & 61 & 37 & 45 & 30 \\
\hline 30 & 1 & 4 & -- & 62 & 37 & 46 & 61 \\
\hline 31 & 1 & 30 & 30 & 63 & 37 & 10 & 30 \\
\hline 32 & 1 & 30 & 30 & 64 & 37 & 60 & 62 \\
\hline
\end{tabular}


Table 4: Forest Value $\left(10^{3} \$ \mathrm{ha}^{-1}\right)$ by stand state under different carbon prices.

\begin{tabular}{|c|c|c|c|c|c|c|c|}
\hline \multirow{2}{*}{$\begin{array}{l}\text { Stand } \\
\text { State }\end{array}$} & \multicolumn{3}{|c|}{ Carbon Price $\left(\$ / \mathrm{tCO}_{2}\right)$} & \multirow{2}{*}{$\begin{array}{l}\text { Stand } \\
\text { State }\end{array}$} & \multicolumn{3}{|c|}{ Carbon Price $\left(\$ / \mathrm{tCO}_{2}\right)$} \\
\hline & 0 & 15 & 30 & & 0 & 15 & 30 \\
\hline 1 & 12 & 23 & 43 & 33 & 35 & 54 & 98 \\
\hline 2 & 23 & 29 & 51 & 34 & 29 & 44 & 84 \\
\hline 3 & 15 & 24 & 48 & 35 & 26 & 30 & 53 \\
\hline 4 & 25 & 27 & 52 & 36 & 32 & 34 & 55 \\
\hline 5 & 26 & 42 & 82 & 37 & 39 & 42 & 48 \\
\hline 6 & 23 & 28 & 56 & 38 & 52 & 57 & 66 \\
\hline 7 & 28 & 44 & 84 & 39 & 49 & 53 & 59 \\
\hline 8 & 12 & 26 & 48 & 40 & 54 & 57 & 70 \\
\hline 9 & 27 & 33 & 84 & 41 & 28 & 31 & 56 \\
\hline 10 & 24 & 33 & 58 & 42 & 33 & 36 & 92 \\
\hline 11 & 29 & 45 & 62 & 43 & 30 & 36 & 60 \\
\hline 12 & 30 & 47 & 89 & 44 & 35 & 50 & 95 \\
\hline 13 & 27 & 31 & 61 & 45 & 51 & 52 & 60 \\
\hline 14 & 32 & 48 & 92 & 46 & 56 & 59 & 95 \\
\hline 15 & 26 & 34 & 58 & 47 & 53 & 56 & 87 \\
\hline 16 & 31 & 48 & 92 & 48 & 58 & 60 & 98 \\
\hline 17 & 28 & 37 & 64 & 49 & 26 & 33 & 67 \\
\hline 18 & 33 & 50 & 95 & 50 & 31 & 46 & 87 \\
\hline 19 & 28 & 44 & 84 & 51 & 28 & 31 & 70 \\
\hline 20 & 25 & 29 & 57 & 52 & 33 & 47 & 90 \\
\hline 21 & 30 & 46 & 87 & 53 & 49 & 50 & 71 \\
\hline 22 & 24 & 31 & 63 & 54 & 54 & 56 & 76 \\
\hline 23 & 29 & 35 & 85 & 55 & 51 & 53 & 74 \\
\hline 24 & 26 & 34 & 68 & 56 & 56 & 57 & 80 \\
\hline 25 & 31 & 37 & 88 & 57 & 30 & 37 & 71 \\
\hline 26 & 27 & 33 & 64 & 58 & 35 & 42 & 95 \\
\hline 27 & 32 & 37 & 92 & 59 & 32 & 37 & 73 \\
\hline 28 & 29 & 35 & 71 & 60 & 37 & 51 & 88 \\
\hline 29 & 34 & 36 & 95 & 61 & 53 & 54 & 76 \\
\hline 30 & 28 & 34 & 90 & 62 & 58 & 60 & 81 \\
\hline 31 & 33 & 52 & 95 & 63 & 55 & 57 & 79 \\
\hline 32 & 30 & 50 & 93 & 64 & 60 & 61 & 91 \\
\hline
\end{tabular}


Table 5: Predicted steady-state probabilities with management under different carbon prices

\begin{tabular}{|c|c|c|c|c|c|c|c|}
\hline \multirow[b]{2}{*}{$\begin{array}{l}\text { Stand } \\
\text { State }\end{array}$} & \multicolumn{3}{|c|}{ Carbon Price $\left(\$ \mathrm{tCO} 2^{-1}\right)$} & \multirow[b]{2}{*}{$\begin{array}{l}\text { Stand } \\
\text { State }\end{array}$} & \multicolumn{3}{|c|}{ Carbon Price $\left(\$ \mathrm{tCO} 2^{-1}\right)$} \\
\hline & 0 & 15 & 30 & & 0 & 15 & 30 \\
\hline 1 & 0.635 & 0.434 & 0.249 & 33 & 0.000 & 0.000 & 0.000 \\
\hline 2 & 0.000 & 0.008 & 0.039 & 34 & 0.000 & 0.007 & 0.010 \\
\hline 3 & 0.262 & 0.051 & 0.148 & 35 & 0.000 & 0.016 & 0.000 \\
\hline 4 & 0.000 & 0.146 & 0.089 & 36 & 0.000 & 0.010 & 0.001 \\
\hline 5 & 0.000 & 0.010 & 0.020 & 37 & 0.102 & 0.004 & 0.029 \\
\hline 6 & 0.000 & 0.006 & 0.002 & 38 & 0.000 & 0.010 & 0.021 \\
\hline 7 & 0.000 & 0.000 & 0.003 & 39 & 0.000 & 0.000 & 0.000 \\
\hline 8 & 0.000 & 0.015 & 0.000 & 40 & 0.000 & 0.000 & 0.022 \\
\hline 9 & 0.000 & 0.005 & 0.020 & 41 & 0.000 & 0.000 & 0.073 \\
\hline 10 & 0.000 & 0.080 & 0.104 & 42 & 0.000 & 0.006 & 0.009 \\
\hline 11 & 0.000 & 0.077 & 0.000 & 43 & 0.000 & 0.000 & 0.007 \\
\hline 12 & 0.000 & 0.000 & 0.000 & 44 & 0.000 & 0.000 & 0.000 \\
\hline 13 & 0.000 & 0.002 & 0.000 & 45 & 0.000 & 0.004 & 0.000 \\
\hline 14 & 0.000 & 0.000 & 0.000 & 46 & 0.000 & 0.000 & 0.000 \\
\hline 15 & 0.000 & 0.023 & 0.011 & 47 & 0.000 & 0.000 & 0.002 \\
\hline 16 & 0.000 & 0.008 & 0.000 & 48 & 0.000 & 0.000 & 0.000 \\
\hline 17 & 0.000 & 0.000 & 0.005 & 49 & 0.000 & 0.000 & 0.014 \\
\hline 18 & 0.000 & 0.000 & 0.000 & 50 & 0.000 & 0.000 & 0.000 \\
\hline 19 & 0.000 & 0.000 & 0.005 & 51 & 0.000 & 0.000 & 0.000 \\
\hline 20 & 0.000 & 0.017 & 0.020 & 52 & 0.000 & 0.000 & 0.000 \\
\hline 21 & 0.000 & 0.000 & 0.000 & 53 & 0.000 & 0.029 & 0.012 \\
\hline 22 & 0.000 & 0.005 & 0.007 & 54 & 0.000 & 0.000 & 0.000 \\
\hline 23 & 0.000 & 0.000 & 0.000 & 55 & 0.000 & 0.000 & 0.000 \\
\hline 24 & 0.000 & 0.000 & 0.037 & 56 & 0.000 & 0.000 & 0.000 \\
\hline 25 & 0.000 & 0.000 & 0.000 & 57 & 0.000 & 0.000 & 0.000 \\
\hline 26 & 0.000 & 0.001 & 0.018 & 58 & 0.000 & 0.000 & 0.001 \\
\hline 27 & 0.000 & 0.009 & 0.001 & 59 & 0.000 & 0.000 & 0.000 \\
\hline 28 & 0.000 & 0.008 & 0.002 & 60 & 0.000 & 0.004 & 0.000 \\
\hline 29 & 0.000 & 0.002 & 0.000 & 61 & 0.000 & 0.000 & 0.008 \\
\hline 30 & 0.000 & 0.003 & 0.009 & 62 & 0.000 & 0.000 & 0.004 \\
\hline 31 & 0.000 & 0.000 & 0.000 & 63 & 0.000 & 0.000 & 0.000 \\
\hline 32 & 0.000 & 0.000 & 0.000 & 64 & 0.000 & 0.000 & 0.000 \\
\hline
\end{tabular}




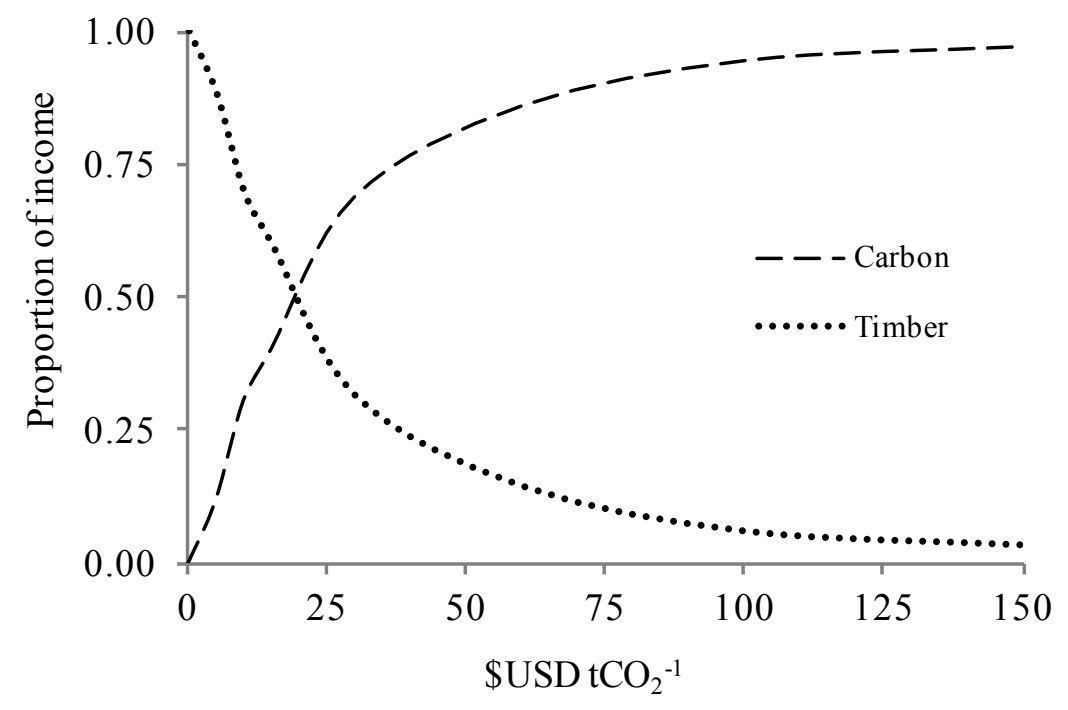

Fig. 1: Proportion of Forest Value attributed to (a) carbon and (b) timber, under different carbon prices.

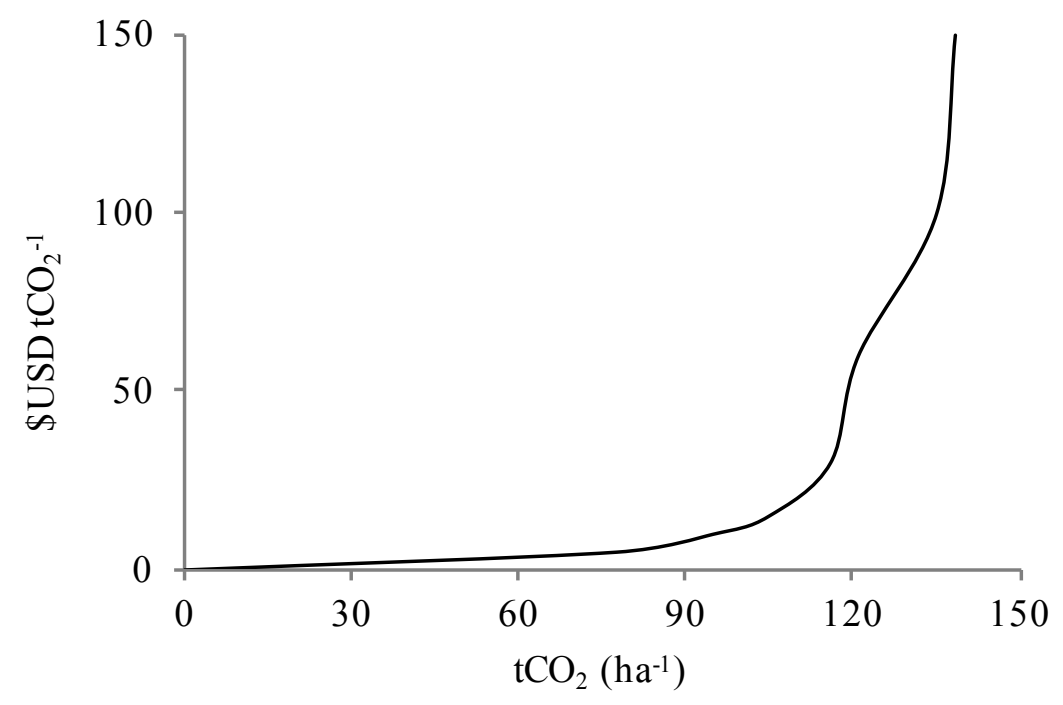

Fig. 2: Economic supply curve for $\mathrm{CO}_{2}$ storage. 


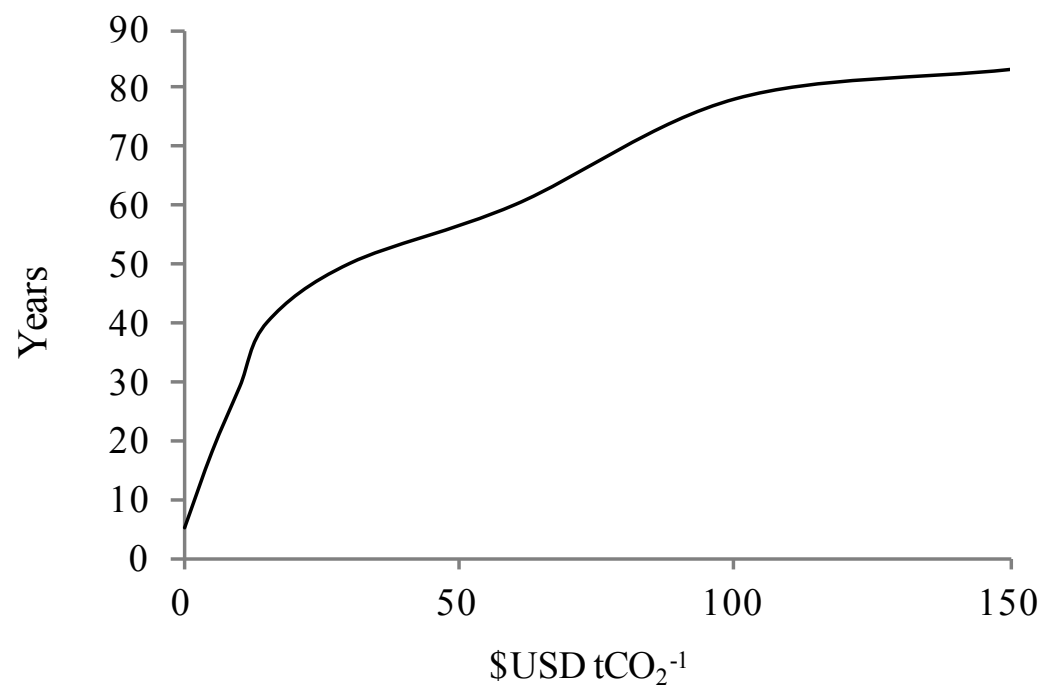

Fig. 3: Expected annual cutting cycle that maximized net present value under different carbon prices. 
(a) Annual harvest volume at max NPV

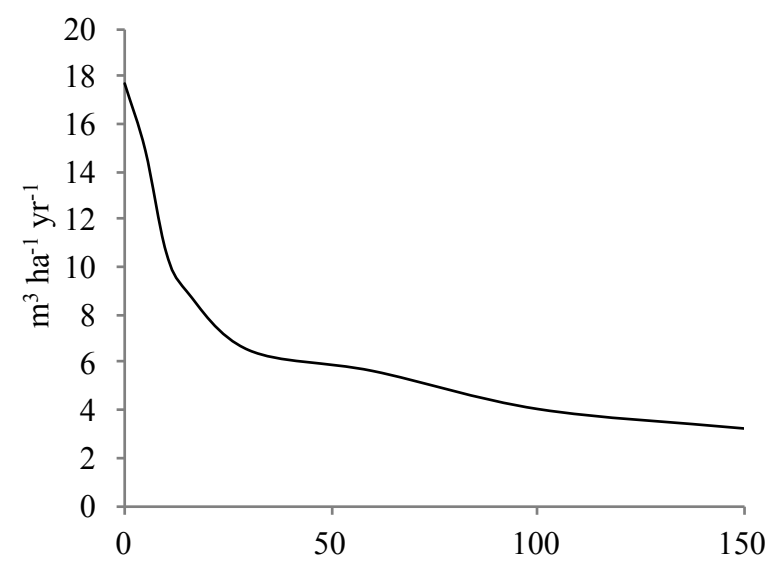

(c) Species diversity at max NPV

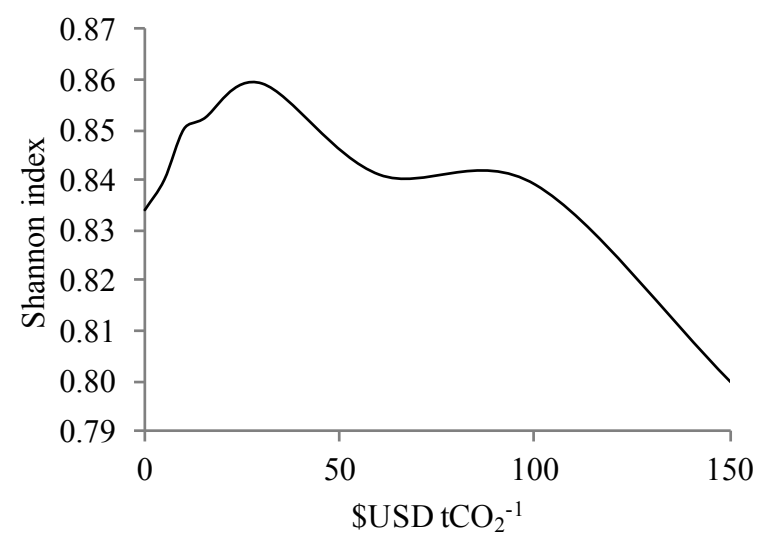

(b) Basal area of large trees at max NPV

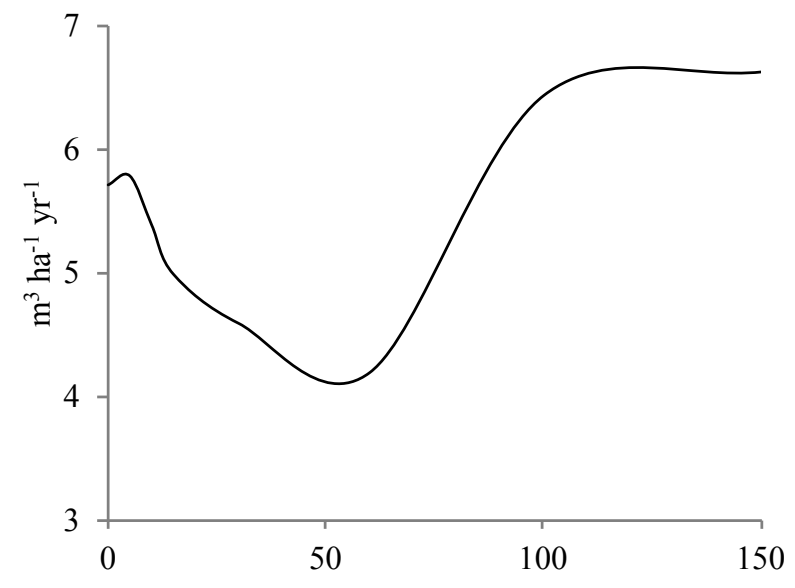

(d) Size diversity at max NPV

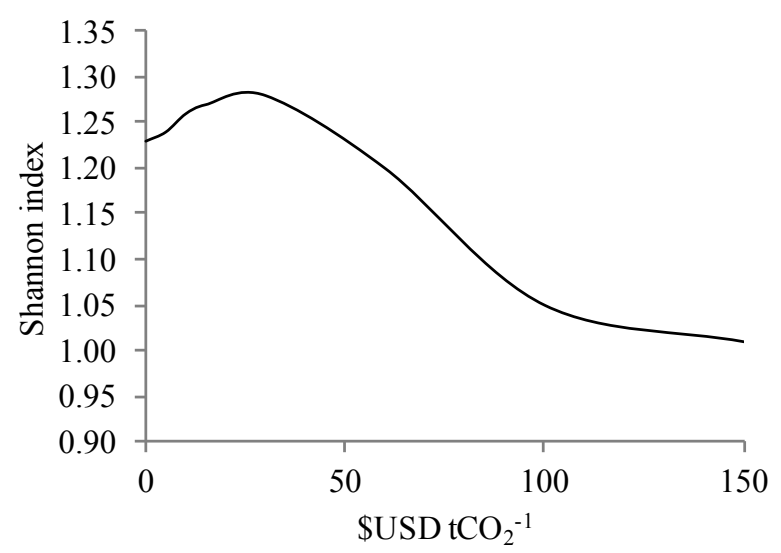

Fig. 4: Effects on (a) annual harvest volume, (b) basal area of large trees, (c) tree species diversity, and (d) tree size diversity for management that maximized net present value under different carbon prices. 